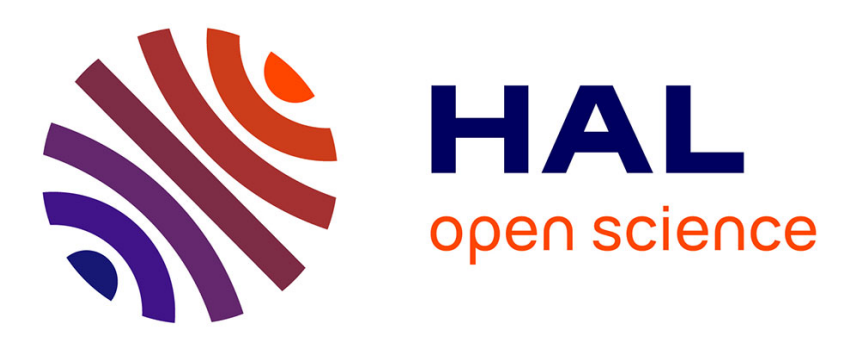

\title{
The curse of knowledge: having access to customer information can reduce monopoly profits
}

Didier Laussel, Ngo Long, Joana Resende

\section{To cite this version:}

Didier Laussel, Ngo Long, Joana Resende. The curse of knowledge: having access to customer information can reduce monopoly profits. RAND Journal of Economics, 2020, 51 (3), pp.650-675. 10.1111/1756-2171.12336 . hal-02941111

\section{HAL Id: hal-02941111 \\ https: / hal-amu.archives-ouvertes.fr/hal-02941111}

Submitted on 31 Jan 2022

HAL is a multi-disciplinary open access archive for the deposit and dissemination of scientific research documents, whether they are published or not. The documents may come from teaching and research institutions in France or abroad, or from public or private research centers.
L'archive ouverte pluridisciplinaire HAL, est destinée au dépôt et à la diffusion de documents scientifiques de niveau recherche, publiés ou non, émanant des établissements d'enseignement et de recherche français ou étrangers, des laboratoires publics ou privés. 


\title{
The Curse of Knowledge: Having Access to Customer Information Can Reduce Monopoly Profits
}

\author{
Didier Laussel, Ngo Van Long ${ }^{\dagger}$ and Joana Resende
}

25th February 2019

\begin{abstract}
We demonstrate the "curse of knowledge" when a monopolist can recognize different consumer groups through their purchase histories, which are influenced by the firm's dynamic pricing policies. Under the Markov-perfect equilibrium, after each commitment period, the firm offers a new introductory price so as to attract new customers. More and more market segments are added gradually. Eventually, the whole market is covered. Shortening the commitment period will result in a fall in profit. In contrast, a full-commitment monopolist prefers to stick to uniform pricing, achieving higher profit. Hence, the firm is better off by refraining from collecting customer information.
\end{abstract}

*Aix-Marseille University (Aix-Marseille School of Economics), CNRS \& EHESS.

${ }^{\dagger}$ Corresponding Author. Department of Economics, McGill University. E-mail: ngo.long@mcgill.ca.

${ }^{\ddagger}$ Cef.up, Economics Department, University of Porto. Email: jresende@fep.up.pt. This research has been financed by project NORTE-01-0145-FEDER-028540 and POCI-01-0145-FEDER-006890. 


\section{Introduction}

The conventional theory of price discrimination tells us that if a monopolist can partition its customer base to construct a segmented market, it will always be profitable to do so even if in each market segment the firm can only use linear pricing. Indeed, the standard model of third-degree price discrimination has shed light on some frequently observed phenomena, such as discounted prices for senior citizens on bus and train travels, students' discounts for admissions to movies or theaters, pensioners' discounts for services such as haircuts, and so on. Market segmentation in these examples is however rather crude, because ages or schooling status are only rough proxies for more relevant characteristics such as income and preferences.

With the advance of information technology and the falling costs of acquiring, maintaining, and analyzing large and sophisticated data bases, a monopolist's dream of a finer partitioning of its customer base is fast becoming a reality. In fact, firms are increasingly able to refine their classification of customers according to their characteristics which are revealed through their individual histories of purchases. In other words, firms are becoming able to define an increasingly refined market segmentation (the hyper-segmentation phenomenon) and then tailor their prices according to the specific features of the consumers in each market segment. ${ }^{1}$

In the case of a monopolist that practises third-degree price discrimination, there is a presumption that with a more refined market segmentation, it can precisely tailor different (linear) prices to different consumer groups, thus increasing its monopoly profit. However, the literature on creating market segments through the acquisition of customer information has overlooked one important aspect: if a firm optimizes over time and its customers are heterogeneous with respect to their maximum willingness to pay, the purchase histories of different groups of customers are endogenously determined by the firm's dynamic pricing policy. Indeed, the number of distinct market segments based on the monopolist's grouping of customer types may well depend on its current, past, and future pricing policies. Anticipating the firm's future prices and grouping strategy, lower-type customers may have an incentive to defer their purchases until later periods in order to receive a better deal. The firm may have to counter this incentive by offering higher informational rents to the new customers it wishes to serve in each period. Under these circumstances,

\footnotetext{
${ }^{1}$ Mohammed (2017) provides some examples of sophisticated price discrimination strategies enabled by new digital technologies.
} 
a firm's ability to acquire information that facilitates a refined classification of customers (in order to practice third-degree price discrimination) might well be detrimental to its stream of profits, given that customers have rational expectations (thereby anticipating the monopolist's intention to reduce its future price in order to attract new cohorts of consumers, with lowest willingness to pay for its good). This suggests that the ability to learn about customers' willingness to pay (and use such information to implement price discrimination strategies based on customer recognition) may be a "curse" rather than an advantage to the monopolist.

The purpose of this paper is to demonstrate the "curse of knowledge" when a monopolist is able to recognize different consumer groups through their purchase histories which are endogenously determined by the firm's dynamic pricing policies. To this end, we set up a simple model of dynamic optimization by a monopolist in continuous time. The monopolist produces a homogenous good (or service) at a constant unit cost. There is a continuum of infinitely-lived consumers. They differ from each other in terms of their willingness to pay for the good. We assume that the (type-dependent) consumers' willingness to pay for the good is private information. Initially, the monopolist knows the distribution of consumer types but it has no information about the true willingness to pay of any consumer. As time goes by, the monopolist can collect some (imperfect) information on consumers' willingness to pay for the good and then use such information to implement third-degree price discrimination practices.

The good (or service) is non-durable, and must be consumed instantaneously. At each instant of time, consuming a second unit would give no utility. Thus, at each point of time, each consumer would buy (and consume) either one unit or none.

We assume that while consumers may purchase and consume at each point of time, the monopolist is committed to making pricing decisions at discrete points in time. The length of the time interval between two consecutive price offers is called the monopolist's "commitment period."

As mentioned above, the firm is able to collect (imperfect) information about consumers' willingness to pay for the good: The firm can never know for sure what is the consumer's exact willingness to pay for the good (i.e. the firm is unable to fully identify if a consumer is of a particular type). However, if a consumer makes her first-time purchase in a given period $n$, the monopolist will label such customer as a vintage- $n$ consumer, clustering her with other consumers who have chosen to buy the good for the first time in 
the same period (suggesting that their willingness to pay for the good is not too different, at least in comparison with the consumers who prefer to buy the good for the first time in a different period). Thanks to the firm's big-data capability, in all its future dealings with the consumer, the firm will be able to recognize this customer as a vintage- $n$ consumer (and price discriminate accordingly). In other words, all those consumers who make their first purchase in period $n$ are "pooled" together: they form a group (a market segment) called vintage- $n$ consumers, with the monopolist being able to charge different prices to each cohort of consumers.

After having been in the market for $n$ periods, the firm faces $n$ groups of former customers, and only one group of new customers. Hence, in each period, the monopolist offers an introductory price that is available only to new customers (this price offer lasts for the duration of the period). The former customers are grouped according to the period in which they made their first purchase. Thus, after being in the market for $n$ periods, the monopolist deals with $n+1$ market segments, and announces $n+1$ contractually fixed prices for the period (one price for each segment). It is important to stress that among all these market segments, $n$ of them are pre-determined in terms of sizes (because the old customers are already classified according to their first-purchase period), while the size of the new market segment is endogenously determined by a number of factors. The first factor is the introductory price that the monopolist offers to this group. The second factor is the decision of each member of the new targeted group as to whether she wants to make her first purchase in that period, or delay her purchase until the next period. This decision depends not only on the consumers' willingness to pay for the good and the current introductory price chosen by the monopolist but also by her expectation of next period's introductory price, as well as the price the consumer expects to face in the future as an old customer.

We suppose that consumers have rational expectations about future prices, and that their decisions concerning when to make their first purchase are rationally made. The firm knows that customers have rational expectations. We are thus dealing with a dynamic game between the firm and the potential new customers.

We compare two scenarios. The first scenario is when the monopolist cannot commit to anything in the future beyond the current period (during which the prices that are set at the beginning of the period remain in force). The current monopolist knows that in the following period his future self will re-optimize, as the latter will have no interest in 
his former self. We call this scenario the Markov-perfect equilibrium (MPE) scenario. We seek to characterize the MPE and obtain comparative-static results.Then, we analyze a second scenario corresponding to a theoretical benchmark in which the monopolist is able to fully commit, right from time $t=0$, to a specified sequence of prices for new and old customers for each vintage.

One of our main findings is that under the full commitment scenario, the monopolist's optimal policy is to refrain from segmenting the market for third degree price discrimination. Instead of inducing market segmentation, it is optimal for the full-commitment monopolist to set a single price which will remain the same in all periods. At the monopolist's optimal price, a subset of low-valuation consumers will be completely excluded from the market, replicating, period after period, the standard static equilibrium outcome. It is worth noting that, in this scenario, the monopolist finds it optimal to treat old customers the same way as new customers. In fact, the firm is optimally committed to the policy that there will be no new customers after the initial period or, in other words, it is optimal to commit to the policy of "no segmentation". Thus, in the commitment scenario, the firm optimally chooses to abstain from collecting information about its customers.

In contrast, under the MPE, a monopolist cannot control his future selves. Thus, as soon as each commitment period has elapsed, the firm offers a new introductory price, lower than last period's introductory price, in order to attract some more first-time customers. This policy creates in each period a new vintage of consumers, which becomes an additional market segment for all future periods. More and more market segments are added as time goes on. Eventually, the whole market is covered. We show that the size of the first market segment (created in the initial period) is smaller, the shorter is the interval of commitment. Interestingly, a shortening of the commitment interval will result in a fall in the firm's aggregate profit. In the limit, as the commitment period tends to zero, the profit vanishes.

Hence, our model without commitment exhibits Coasian dynamics in terms of profits, even though the good is non-durable. The rationale behind this result is the following: since consumers expect the firm to expand the market in future periods, they have an incentive to delay their purchase to take advantage of future low prices for new customers. To counter this incentive, the firm must increase the informational rent of the marginal customer of each vintage.

In light of this concession, we also find that the monopolist's profit under the MPE is 
strictly lower than the profit under full commitment. Thus, the firm is paradoxically hurt when it is able to recognize its consumers and use this information to implement price discrimination based on the consumers' decision to buy the good for the first time. We call this the Curse of Knowledge.

Accordingly, our findings suggest that there is indeed such a thing as blessed ignorance and the monopolist would actually be better off if it were unable to keep any records about its customers. Hence, in our set-up, public policies aiming at limiting firms' ability to collect and keep data on their customers (such as the General Data Protection Regulation (GDPR) in the European Union) would end up benefitting the monopolist, allowing the firm to avoid the curse of knowledge.

The rest of the paper is organized as follows: Section 2 presents a very brief overview of the related literature. Section 3 introduces the main ingredients of the model. Section 4 analyzes the MPE. Section 5 analyzes equilibrium outcomes arising in the full commitment scenario, comparing them to the MPE. Section 6 investigates the consumer surplus and welfare under MPE. Finally, Section 7 concludes.

\section{Related literature}

Our model is related to three strands of literature. The first strand deals with third-degree price discrimination in a static framework, where a monopolist partitions his customer base into several market segments and charges different unit prices for different segments. For a textbook exposition and literature review of this strand of literature, see Tirole (1988). ${ }^{2}$ The second strand of literature refers to the study of "behavior-based price discrimination" (e.g.Fudenberg and Tirole, 2000; Chen, 1997; or, more recently, Choe et al., 2018 ${ }^{3}$ ). This literature looks at markets where firms are able to learn about consumers' preferences by accessing data about their histories of purchases, considering that firms use

\footnotetext{
${ }^{2}$ See in particular, Tirole's Chapter 3, Section 3.2, titled "Multimarket (Third-Degree) Price Discrimination." (pp. 137-142.)

${ }^{3}$ Chen (1997) focus on oligooply markets, looking at behavior-based price discrimination based on consumers' switching costs. Fudenberg and Tirole (2000) analyze behavior based price discrimination when firms compete à la Hotelling in a two-period framework. Each firm learns where each consumer purchases in the first period, but firms have not finer details about consumers preferences. Hence, in the second period, they practice third degree price discrimination. In Choe, King and Matsushima (2018), a firm knows more about its own customers than its rival does, implementing personalized prices within its own turf. They show that there are multiple equilibria.
} 
this information to practice third degree price discrimination in subsequent interactions with their customers (see Fudenberg and Villas-Boas, 2006 for a survey). Most papers in this strand of literature assume a two-period model and focus on duopoly competition. ${ }^{4}$ The third strand of literature studies the market dynamics of a durable-good monopoly, and shows that a monopolist's inability to fully commit to its future prices would lose all his monopoly power if the time interval between two consecutive price offers goes to zero (Coase, 1972; Bulow, 1982; Bond and Samuelson, 1987; Kahn, 1987; Karp, 1996; Laussel et al., 2015; among others. See Long (2015) for a survey.)

We extend the standard third-degree price discrimination model by considering an infinite-horizon model in which a monopolist gradually learns to identify consumers and gradually creates additional market segments in order to practice third-degree price discrimination (based on the moment that each cohort of consumer chooses to buy the good for the first time). Our model assumes that there is a continuum of heterogeneous consumers who differ from one another in terms of their maximum willingness to pay for the good. That is, customers' intensities of preferences are private information. Since the firm can only produce a homogeneous good (i.e., quality discrimination is not possible) and each customer consumes only one unit of the good (i.e., there is no possibility to offer quantity discounts), it is not possible to induce consumers to reveal their individual types without some pooling. By combining the three strands of literature, we show that a monopolist that cannot commit will create a new market segment in every period from a new set of first-time customers. Paradoxically, the firm will obtain lower aggregate profit than a monopolist that cannot learn anything about its customers. We are then able to obtain a striking result, which we call "the curse of knowledge": the monopolist's ability to learn about consumers' preferences, combined with his inability to commit to future prices and to future market expansion strategies, can be detrimental to his profit, and in the limit, as the length of the time interval that must elapse before a new market segment is created tends to zero, the monopolist's profit vanishes. This allows us to make the point that the Coase's conjecture, which was established for the case of durable goods, may hold as well when we look at a monopolist that produces non-durable goods (and implements third degree price discrimination based on customer recognition).

\footnotetext{
${ }^{4}$ Following the seminal works by Fudenberg and Tirole (2000) and Chen (1996) a vast number of authors have investigated the competitive effects of behavior based price discrimination. Some examples include (but are not limited to) the works by Chen and Pearcy (2010), Esteves (2009, 2010), Gherig et al. (2011, 2012), Villas Boas (1999).
} 
Our paper is also related to the literature on Markov-perfect equilibrium in games involving interactions between firms and infinitely-lived consumers with rational expectations (see, e.g., Driskill and McCafferty, 2001; Laussel, Montmarin and Long, 2004; Laussel, Long and Resende, 2015; Long, 2015).

\section{The Model}

A monopolist produces a non-durable good (or a service) at a constant marginal cost which is normalized to zero. Although the good is undifferentiated (i.e., all units have the same quality), consumers have heterogeneous willingness to pay for the good.

There is a continuum of consumer types who live forever. Time is a continuous variable. Each consumer buys and instantaneously consumes at most one unit of the good at each instant of time. We let $\theta$ be a variable denoting the type of a consumer. A consumer of type $\theta$ derives $\theta$ units of utility for consuming one unit of the good per unit of time. If she pays the unit price $p$ for the good, her instantaneous net utility is $\theta-p$. We assume that the support of the distribution of $\theta$ is a closed set $[\underline{\theta}, \bar{\theta}]$.

The firm enters the market at time $t=0$. It partitions the (non-negative) time line $[0, \infty)$ into a sequence of "commitment periods" of equal length $\Delta$. Thus, period 0 corresponds to the interval $[0, \Delta)$ of the time line and period $n$ corresponds to the interval $[n \Delta,(n+1) \Delta)$, where $n=0,1,2,3, \ldots$ A customer who buys the good for the first time in period $i$ is called a vintage- $i$ consumer. The collection of all customers of the same vintage constitutes a market segment. At the beginning of any period $n$, the monopolist offers to all former consumers of vintage $i$ (where $i<n$ ) a vintage-specific price $p(n, i)$ at which they can purchase a unit of the good at each instant of time in the time interval $[n \Delta,(n+1) \Delta)$. We assume that, thanks to the firm's "big-data" capability, the monopolist can identify the vintage of all its former customers. The monopolist practices third degree price discrimination: a consumer of vintage $i<n$ can acquire the good in period $n$ only at the price $p(n, i)$ and not at any other prices. Customers who buy the good for the first time in period $n$ are offered an "introductory" price $p(n, n)$.

For all $i=0,1,2, . ., n$, a consumer of vintage $i$ who purchases and consumes a unit of the good at each point of time in period $n \geq i$ enjoys the instantaneous net utility $\theta-p(n, i)$. Her net utility over the whole period $n$ (discounted back to the beginning of period $n)$ is 


$$
\begin{aligned}
v(\theta, n, i) & \equiv(\theta-p(n, i)) \int_{0}^{\Delta} e^{-r \tau} d \tau \equiv(\theta-p(n, i)) \frac{1}{r}\left(1-e^{-r \Delta}\right) \\
& \equiv(\theta-p(n, i)) \frac{1-\beta}{r}
\end{aligned}
$$

Here $r>0$ denotes the instantaneous discount rate, and $\beta$ the discount factor between periods, $\beta \equiv e^{-r \Delta}$. Note that $r$ is exogenous and independent of $\Delta$, while $\beta$ depends on $\Delta$. Clearly $\beta \rightarrow 1$ when $\Delta \rightarrow 0$.

Let us consider the case where the monopolist cannot commit to future prices. Specifically, when selling to first-time consumers in period $n$, the firm cannot commit to offer them in future periods the same price as the introductory price. In addition, in any period $n$, the monopolist cannot commit to offer pre-determined introductory prices to future new customers. In the absence of such a commitment capability, we assume the monopolist uses third-degree discrimination with respect to old market segments: they are discriminated with respect to the date of first entry into the market.

The cumulative distribution of $\theta$ is denoted by $F(\theta)$ and the density function is denoted by $f(\theta)$. We make the following assumptions:

Assumption 1: $f(\theta)-\theta f^{\prime}(\theta) \geq 0$

Assumption 2: $1-\underline{\theta} f(\underline{\theta})>0$

Assumption 1 is sufficient to ensure that the monopolist's profit function for period $n$ for each market segment $i<n$ is concave in the price $p(n, i)$. This assumption is satisfied by the uniform distribution and, more generally, by all distributions such that $F$ is not too convex. Assumption 2 ensures that a static monopolist would not serve the whole market. In the uniform distribution case, it is equivalent to $\bar{\theta}>2 \underline{\theta}$.

\section{Equilibrium under non-commitment}

We start our analysis of the model by scrutinizing the monopolist's third degree price discrimination among former customers. This will be followed by an examination of the optimal pricing for new customers. 


\subsection{Third-degree price discrimination among former customers}

The following observation is useful in what follows. Since consumers are rational, we can deduce that, in equilibrium, if a consumer of type $\theta^{\prime}$ finds it optimal to be a first-time customer in period $j \geq 0$, then any consumer of type $\theta^{\prime \prime}>\theta^{\prime}$ must find it optimal to be a first-time customer in some period $i$, with $i \leq j$. Thus, at the beginning of any period $j+1$, there are $j$ cut-off types $\theta_{1} \geq \theta_{2} \geq \theta_{3} \geq \ldots \geq \theta_{j+1}$ such that new customers in period 0 are of type $\theta \in\left(\theta_{1}, \bar{\theta}\right]$, new customers in period 1 are of type $\theta \in\left(\theta_{2}, \theta_{1}\right]$, and so on. Customers of type $\theta \in\left(\theta_{j+1}, \theta_{j}\right]$ are called vintage- $j$ customers. A customer of type $\theta_{j+1}$ is called a vintage- $j$ marginal customer. In equilibrium, a vintage- $j$ marginal customer is indifferent between making her first purchase in period $j$ or in period $j+1$. Thanks to the firms' ability to keep its data records registering the moment in which each consumer enters the market, the firm is able to identify the vintage of a former customer when she comes back in subsequent periods. The firm cannot tell the difference among former customers that belong to the same vintage.

At the beginning of period $j$, all consumers whose types belong to $\left(\theta_{j}, \bar{\theta}\right]$ have already purchased the good at least once in previous periods. The monopolist would not offer a former customer the introductory price that it offers to new customers. In any period $j$, the firm offers former customers a vintage-dependent price, $p(i, j)$, for each vintage $i<j$ $(i=0,1,2, . ., j-1)$ so as to maximize the profits it makes from them. The population share of customers that belong to vintage $i$ is $F\left(\theta_{i}\right)-F\left(\theta_{i+1}\right)$. Clearly, offering these customers any $p(i, j)>\theta_{i}$ would be a dominated strategy because it would result in zero demand from that market segment. Thus, in period $j$, for former customers that belong to vintage- $i$ (where $i<j$ ), the monopolist will offer a price $p(i, j) \leq \theta_{i}$. The quantity sold in period $j$ to this market segment is

$$
Q_{i, j}=\left\{\begin{array}{cc}
F\left(\theta_{i}\right)-F(p(i, j)) & \text { if } \theta_{i+1} \leq p(i, j) \leq \theta_{i} \\
F\left(\theta_{i}\right)-F\left(\theta_{i+1}\right) & \text { if } 0 \leq p(i, j) \leq \theta_{i+1}
\end{array}\right.
$$

Thus, the profit obtained in period $j$ from this market segment is

$$
\pi(i, j)=\frac{1-\beta}{r}\left[F\left(\theta_{i}\right)-\max \left\{F\left(\theta_{i+1}\right), F(p(i, j))\right\}\right] p(i, j) .
$$


Let us define $p\left(\theta_{i}\right)$ as the solution of the following unconstrained problem

$$
\max _{p}\left[F\left(\theta_{i}\right)-F(p)\right] p
$$

Then $p\left(\theta_{i}\right)$ satisfies the first order condition: ${ }^{5}$

$$
F\left(\theta_{i}\right)-F\left(p\left(\theta_{i}\right)\right)-f\left(p\left(\theta_{i}\right)\right) p\left(\theta_{i}\right)=0
$$

(Note that $p\left(\theta_{i}\right)=\frac{\theta_{i}}{2}$ in the case of a uniform distribution.)

Clearly there is no point in offering former customers of vintage $i$ a price that is below the lowest valuation among them, $\theta_{j+1}$. Consequently, the monopolist's optimal choice must satisfy the condition $p^{*}(i, j) \geq \theta_{i+1}$. Accordingly, the optimal price is

$$
p^{*}(i, j)=\max \left\{p\left(\theta_{i}\right), \theta_{i+1}\right\} \text { for all } i \leq j .
$$

It follows that if $p\left(\theta_{i}\right) \leq \theta_{i+1}$, then the monopolist's optimal price for former vintage- $i$ customers is exactly equal to $\theta_{i+1}$, i.e., the price is equal to the maximum willingness to pay of the lowest valuation customers in vintage $i$. We will show later that along the optimal path, the property $p\left(\theta_{i}\right) \leq \theta_{i+1}$ is indeed satisfied. For future reference, we record the following result as Lemma 1 :

Lemma 1: Under the assumption that $p\left(\theta_{i}\right) \leq \theta_{i+1}$ (which will be showed to be satisfied in equilibrium), in all periods $j>i$, the monopolist's optimal price for market segment $i$ is equal the maximum willingness to pay of the lowest type of that segment:

$$
p^{*}(i, j)=\theta_{i+1}
$$

In view of equation (2), the monopolist's optimal aggregate profit in period $n$ over all the former customers is

$$
\Pi_{n}^{F}=\frac{1-\beta}{r} \sum_{i=1}^{i=n}\left(F\left(\theta_{i-1}\right)-F\left(\theta_{i}\right)\right) \theta_{i} .
$$

where the superscript $F$ stands for "former" customers.

\footnotetext{
${ }^{5}$ The SOC is always satisfied thanks to Assumption 1.
} 


\subsection{Monopoly pricing for first-time customers}

Let us now turn to new customers in period $n$. Let $U_{n}\left(\theta_{n+1}\right)$ denote the intertemporal net utility of period- $n$ marginal new customer. By marginal, we mean that she is indifferent between (i) being a first-time customer in period $n$ (paying the price $p(n, n)$ for the good), and (ii) being a first-time customer in period $n+1$, paying a lower price $p(n+1, n+1)<$ $p(n, n)$, but at the cost of having to forgo her net utility $\theta_{n+1}-p(n, n)$ at each instant of time over the time interval of length $\Delta$.

Recall that Lemma 1 stated that marginal customers in period $n$ will be charged an instantaneous price $p^{*}(n, j)=\theta_{n+1}$ in all later periods $j>n$. Thus, they get zero utility in all later periods. It follows that their intertemporal utility from period $n$ onwards is simply equal to their utility in period $n$, that is $U_{n}\left(\theta_{n+1}\right)=\frac{1-\beta}{r}\left(\theta_{n+1}-p(n, n)\right)$. It is useful to re-write this condition as

$$
p(n, n)=\theta_{n+1}-\frac{r}{1-\beta} U_{n}\left(\theta_{n+1}\right) .
$$

We will refer to $U_{n}\left(\theta_{n+1}\right)$ as the informational rent of period-n marginal new customer.

The period- $n$ profit over all new customers may be written as

$$
\Pi_{n}^{N}=\left(\frac{1-\beta}{r}\right)\left[F\left(\theta_{n}\right)-F\left(\theta_{n+1}\right)\right] p(n, n)
$$

Substituting for $p(n, n)$, we obtain

$$
\Pi_{n}^{N}=\left[F\left(\theta_{n}\right)-F\left(\theta_{n+1}\right)\right]\left(\theta_{n+1} \frac{1-\beta}{r}-U_{n}\left(\theta_{n+1}\right)\right) .
$$

Now, any vintage- $n$ customer of type $\theta>\theta_{n+1}$ will face the same present and future prices as the ones that the marginal customer $\theta_{n+1}$ faces, but values the good more. Therefore, the difference in their intertemporal net utility is

$$
U_{n}(\theta)-U_{n}\left(\theta_{n+1}\right)=\frac{1}{r}\left(\theta-\theta_{n+1}\right)
$$

If the firm wants to induce a new customer with $\theta \in\left[\theta_{n+1}, \theta_{n}\right]$ to buy in period $n$ it must ensure that she would not be better off waiting until period $n+1$. This participation constraint may be written as 


$$
\frac{1}{r}\left(\theta-\theta_{n+1}\right)+U_{n}\left(\theta_{n+1}\right) \geq \beta\left[\frac{1}{r}\left(\theta-\theta_{n+2}\right)+U_{n+1}\left(\theta_{n+2}\right)\right] \text { for all } \theta \in\left[\theta_{n+1}, \theta_{n}\right]
$$

From (6), the LHS is simply $U_{n}(\theta)$ which is the intertemporal utility obtained by a type- $\theta$ customer who chooses to be a period- $n$ new customer. ${ }^{6}$ The RHS is the alternative intertemporal utility, measured from period $n$, that she would obtain if she chose to be a new customer in period $n+1$. It is obtained as $\beta$ times the sum of the period $n+1$ net utility $\frac{1-\beta}{r}\left(\theta-\theta_{n+2}\right)+U_{n+1}\left(\theta_{n+2}\right)$ and the aggregate discounted utility $\frac{\beta}{r}\left(\theta-\theta_{n+2}\right)$ in all periods $i \geq n+2$. Notice that if the participation constraint (7) is satisfied for type $\theta=\theta_{n+1}$ (the marginal customer), it will also be satisfied for all customers of type $\theta \in\left(\theta_{n+1}, \theta\right]$. Thus, the constraint (7) is redundant if the following simpler constraint is satisfied: $U_{n}\left(\theta_{n+1}\right) \geq \beta\left[\frac{1}{r}\left(\theta_{n+1}-\theta_{n+2}\right)+U_{n+1}\left(\theta_{n+2}\right)\right]$. In fact, the latter constraint is satisfied with equality,

$$
U_{n}\left(\theta_{n+1}\right)=\beta\left(\frac{1}{r}\left(\theta_{n+1}-\theta_{n+2}\right)+U_{n+1}\left(\theta_{n+2}\right)\right)
$$

because, by definition, a marginal customer is indifferent between being a first-time customer in period $n$ and being a first-time customer in period $n+1$. By repeated substitution, the difference equation (8) yields the solution

$$
U_{n}\left(\theta_{n+1}\right)=\frac{1}{r} \sum_{j=1}^{\infty} \beta^{j}[\theta(n+j)-\theta(n+j+1)]
$$

where we have used the fact that, since $U$ is bounded, it holds that

$$
\lim _{j \rightarrow \infty} \beta^{j} U_{n+j}\left(\theta_{n+j+1}\right)=0
$$

\subsection{The Markov Perfect Equilibrium}

In any period $n$, let $X(n) \in[0,1]$ denote the fraction of the total population that has purchased the good prior to that period. Given the nature of our problem, $X(n)$ would

\footnotetext{
${ }^{6}$ It is the sum of the period $n$ net utility $\frac{1-\beta}{r}\left(\theta-\theta_{n+1}\right)+U_{n}\left(\theta_{n+1}\right)$ and the aggregate discounted utility $\frac{\beta}{r}\left(\theta-\theta_{n+1}\right)$ in all periods $i \geq n+1$.
} 
be a natural state variable for our dynamic problem. However, it turns out to be more convenient to use as state variable the following transformation of $X(n)$. We define the state variable $\Theta(n)$ by

$$
\Theta(n) \equiv F^{-1}(1-X(n)),
$$

where $F($.$) is the cumulative distribution of \theta$. Then $\Theta(0)=\bar{\theta} \equiv \theta_{0}$, and $\Theta(n) \in[\underline{\theta}, \bar{\theta}]$.

Since the firm's optimal pricing for former customers is already solved, the dynamic optimization problem reduces to determining, in each period $n$, given the state variable $\Theta(n)$, the optimal size of the new market segment. That is, given $\Theta(n)$, the firm wants to choose the optimal $\Theta(n+1)$. It follows the firm's Markovian strategy consists of a cut-off rule $\psi$, such that $\Theta(n+1)=\psi(\Theta(n) \leq \Theta(n)$.

Consumers have a Markovian expectations rule $\Omega($.$) that predicts the life-time rent of$ the marginal first-time customer in period $n$, i.e., $U_{n}\left(\theta_{n+1}\right)$. Rational expectations require that, given (9), we have

$$
\Omega(\Theta(n))=\frac{1}{r} \sum_{j=1}^{\infty} \beta^{j}\left(\Theta^{*}(n+j)-\Theta^{*}(n+j+1)\right)=U_{n}\left(\theta_{n+1}\right),
$$

where $\left\{\Theta^{*}(.)\right\}_{n}^{\infty}$ is the path of the state variable $\Theta$ induced by the strategy of the monopolist.

A Markovian strategy $\psi($.$) chosen by the monopolist is called a best reply to the$ consumer expectations function $\Omega\left(\right.$.) if (a) it yields a sequence of cut-off values $\theta_{n+1}$ that maximize profits, starting from any pair $(n, \Theta(n))$, and (b) the rational expectations condition (10) is satisfied by such a sequence.

In what follows, we suppose that the distribution of types is uniform on $[0,1]$. Then, using (3), the profit obtained in period $n$ from old customers is

$$
\Pi_{n}^{F}=\frac{1-\beta}{r} \sum_{i=1}^{i=n}\left(\theta_{i-1}-\theta_{i}\right) \theta_{i}
$$

Corresponding to eq. (5), the profit obtained in period $n$ from first-time customers in that period is

$$
\Pi_{n}^{N}=\left(\theta_{n}-\theta_{n+1}\right)\left(\theta_{n+1} \frac{1-\beta}{r}-\Omega(\Theta(n))\right),
$$


where we have substituted $\Omega(\Theta(n))$ for $U_{n}\left(\theta_{n+1}\right)$ because of the rational expectations requirement.

It follows that the Bellman equation for the monopolist is ${ }^{7}$

$$
\begin{aligned}
V(\Theta(n))= & \max _{\Theta(n+1)}\left\{\frac{1-\beta}{r} \sum_{i=1}^{i=n}(\Theta(i-1)-\Theta(i)) \Theta(i)\right)+ \\
& \left.(\Theta(n)-\Theta(n+1))\left(\Theta(n+1) \frac{1-\beta}{r}-\Omega(\Theta(n))\right)+\beta V(\Theta(n+1))\right\} .
\end{aligned}
$$

Given the uniform distribution assumption and the general structure of the problem, we conjecture the existence of a linear cut-off rule

$$
\Theta(n+1)=\psi(\Theta(n))=\gamma \Theta(n)
$$

and a linear expectations function ${ }^{8}$

$$
\Omega(\Theta(n))=\lambda \Theta(n)
$$

where both $\gamma$ and $\lambda$ are to be determined. Notice that, since $\underline{\theta}=0$, the conjectured consumers' expectations function satisfies the obvious requirement that if the lowest type to be served as first-time customers in period $n$ is $\theta_{n+1}=\underline{\theta}=0$, then it must hold that they enjoy zero informational rent. ${ }^{9}$

Given the monopolist's cut-off parameter $\gamma$, using our conjectured expectations rule (13), the rational expectations requirement, with the help of equation (8), can be rewritten as

$$
\lambda \theta_{n}=\beta\left(\lambda \theta_{n+1}+\frac{1}{r}\left(\theta_{n+1}-\theta_{n+2}\right)\right) .
$$

Using the conjectured equilibrium cut-off rule, we have $\Theta(n+1)=\gamma \Theta(n)$ and $\Theta(n+$

${ }^{7} V(\Theta(n))$ depends also on $\Theta(n-1), \Theta(n-2), . ., \Theta(0)$, i.e., on all the past values of the state variable. This is omitted for the sake of notational simplicity. Note that in period $n$ the given values $\Theta(n-1)$, $\Theta(n-2), . ., \Theta(0)$ have no relevance for the decision on the optimal $\Theta(n+1)$. Only $\Theta(n)$ is relevant.

${ }^{8}$ Starting from a more general conjectured linear-quadratic expectations functions would lead to a simple linear expectations function, so we take this shortcut for the sake of simplicity.

${ }^{9}$ This is the reason why we suppose $\underline{\theta}=0$. Were $\underline{\theta}>0$, there would exist no MPE with linear (or linear-quadratic) expectations and cut-off rules. 
2) $=\gamma^{2} \Theta(n)$, and equation (14) becomes

$$
\lambda \theta_{n}=\beta\left(\lambda \gamma \theta_{n}+\frac{1}{r}\left(\gamma \theta_{n}-\gamma^{2} \theta_{n}\right)\right)
$$

from which we obtain

$$
r \lambda=\frac{\beta\left(\gamma-\gamma^{2}\right)}{1-\beta \gamma}
$$

This equation says that, given the monopolist's cut-off rule, represented by $\gamma$, the consumers expectations are rational (best reply) if and only if

$$
\lambda=\lambda(\gamma ; \beta, r)=\frac{\beta\left(\gamma-\gamma^{2}\right)}{r(1-\beta \gamma)}
$$

Maximizing now the Bellman equation with respect to $\Theta(n+1)$, one obtains the first-order condition

$$
(1-\beta) \frac{\Theta(n)-2 \Theta(n+1)}{r}+\lambda \Theta(n)+\beta V^{\prime}(\Theta(n+1))=0,
$$

where $V^{\prime}$ denotes the derivative of the value function.

Differentiating the Bellman equation with respect to $\Theta(n)$ and using the Envelope Theorem, we obtain

$$
V^{\prime}(\Theta(n))=\frac{1-\beta}{r}[\Theta(n-1)-2 \Theta(n)+\Theta(n+1)]-\lambda \Theta(n)-\lambda[\Theta(n)-\Theta(n+1)]
$$

From (18), we can obtain an expression for $\beta V^{\prime}(\Theta(n+1))$ and substitute it into (17). We finally obtain the Euler equation,

$$
\frac{1}{r}\left[\left(1-\beta^{2}+r \lambda\right) \Theta(n)-2\left(1-\beta^{2}+\beta r \lambda\right) \Theta(n+1)+\beta(1-\beta+r \lambda) \Theta(n+2)\right]=0 .
$$

This equation is satisfied if the monopolist uses a linear cut-off rule, so that $\Theta(n+2)=$ $\gamma \Theta(n+1)=\gamma^{2} \Theta(n)$. Then we obtain

$$
\frac{1}{r}\left[\left(1-\beta^{2}+r \lambda\right)-2\left(1-\beta^{2}+\beta r \lambda\right) \gamma+\beta(1-\beta+r \lambda) \gamma^{2}\right]=0
$$


Equation (20) says that, taking the consumers' expectation rule as given, the monopolist's linear cut-off rule is an optimal response (best reply): $\gamma=\gamma(\lambda ; \beta, r)$, i.e.,

$$
\gamma=\frac{2\left(1-\beta^{2}+\beta r \lambda\right) \pm \sqrt{4\left(1-\beta^{2}+\beta r \lambda\right)^{2}-4\left(1-\beta^{2}+r \lambda\right) \beta(1-\beta+r \lambda)}}{2 \beta(1-\beta+r \lambda)}
$$

The two best-response functions (16) and (21) yield a unique fixed point $\left(\gamma^{*}, \lambda^{*}\right)$ which characterizes the Markov-perfect Nash equilibrium. Indeed, we can show that, for any given $\beta \in(0,1), \gamma^{*}$ is the unique positive real root of the equation

$$
1-\beta^{2}+\left(-2+2 \beta^{2}+\beta^{3}\right) \gamma+\left(2 \beta-3 \beta^{2}-2 \beta^{3}\right) \gamma^{2}+\left(2 \beta^{2}+\beta^{3}\right) \gamma^{3}-\beta^{2} \gamma^{4}=0
$$

This is a polynomial of degree 4 in $\gamma$. With $0<\beta<1$, we find that the polynomial has a unique positive real root $\gamma^{*}$. In the limiting case where $\beta=0$, we have $\gamma^{*}=1 / 2$, and when $\beta=1$, we have $\gamma^{*}=1 .^{10}$ Figure 1 shows that $\gamma^{*}$ is strictly increasing in $\beta$. In the figure, the $x$-axis represents $\beta$, whereas the vertical axis represents the equilibrium value of $\gamma$ as a function of $\beta$.

\section{FIGURE 1}

Proposition 1 summarizes the analytical characterization of our MPE.

Proposition 1: There exists a MPE $\left(\gamma^{*}, \lambda^{*}\right)$ such that $\gamma^{*}(\beta) \in\left[\frac{1}{2}, 1\right]$ is the solution of

$$
E(\beta, \gamma)=1-\beta^{2}+\left(-2+2 \beta^{2}+\beta^{3}\right) \gamma+\left(2 \beta-3 \beta^{2}-2 \beta^{3}\right) \gamma^{2}+\left(2 \beta^{2}+\beta^{3}\right) \gamma^{3}-\beta^{2} \gamma^{4}=0
$$

and $\lambda^{*}$ is given by

$$
\lambda^{*}=\frac{\beta\left(\gamma^{*}(\beta)-\gamma^{*}(\beta)^{2}\right)}{r\left(1-\beta \gamma^{*}(\beta)\right)}
$$

\footnotetext{
${ }^{10}$ For $\beta=1, \gamma=0$ is also a real root. It is the limit when $\beta \rightarrow 1$ of a negative real root and as such may be ruled out.
} 
Proof: See the Appendix.

Since $\underline{\theta}=0$, the maximum possible market size is $\bar{\theta}-\underline{\theta}=\bar{\theta}$. The measure of customers that have been served at the end of period $n$ is $\left(1-\gamma^{n+1}\right) \bar{\theta}$. Thus the market is gradually fully covered only asymptotically, as $n$ tends to infinity. Our eventual full coverage result provides a sharp contrast to the static equilibrium case and, as we shall see, also to the dynamic case with commitment, as in both of these cases only partial coverage occurs.

Let us scrutinize the role of the length of the commitment period, $\Delta$. A natural enquiry is whether a shortening of the commitment period will make the market coverage bigger at any given point of time. Let $t$ be a continuous variable denoting time, where $t=0$ is the beginning of period 0 (which is the first period), and, more generally, $t=n \Delta$ at the beginning of period $n$. Recall that $\gamma$ is a function of $\beta \equiv e^{-r \Delta}$. Therefore the fraction of the consumer base that is served by the monopolist at time $t$ is given by

$$
M(t ; \Delta, r) \equiv\left[1-\left(\gamma\left(e^{-r \Delta}\right)\right)^{\frac{t}{\Delta}+1}\right] .
$$

Let us investigate how, at any given $t$, the market coverage $M(t ; \Delta, r)$ depends on $\Delta$. A shortening of $\Delta$ generates two opposite effects. On one hand, since $\gamma^{\prime}(\beta)>0, \gamma$ increases as $\Delta$ gets shorter, i.e., the market expansion from one period to the next is smaller (meaning the monopolist is doing a finer partition of its customers). On the other hand, the interval between two periods becomes smaller and thus over any time interval $[0, t]$ market expansions occur more often (leading to faster market expansion).

Figure 2 shows that the latter effect outweighs the former effect: for any given $r>0$, a shortening of the commitment period $\Delta$ speeds up market expansion. This dynamics is clearly Coasian. ${ }^{11}$

\section{FIGURE 2}

We prove in Claim 1 below that full coverage occurs instantaneously when $\Delta$ becomes infinitesimal, meaning that all consumers will be served in a twinkle of an eye when $\Delta$ becomes infinitesimal.

\footnotetext{
${ }^{11}$ Coase shows that if a durable-good monopolist can supply to a new set of customers after selling to the previous set of customers, then, if the time interval that must elapse between two consecutive offers decreases to zero, the whole market will be covered in a twinkle of an eye.
} 
Claim 1: When the length of time $\Delta$ between two different proposals to two consecutive sets of new customers becomes infinitesimal, the market is covered instantaneously. For any given time $t>0$, as the length of the period of commitment $\Delta$ tends to 0 , the fraction of the customer base that has been served up to that time tends to $\left(1-e^{-\gamma^{\prime}(1) r t}\right)$, which equals 1 since $\gamma^{\prime}(\beta) \rightarrow+\infty$ as $\beta \rightarrow 1$ :

$$
\lim _{\Delta \rightarrow 0} \gamma\left(e^{-r \Delta \frac{t}{\Delta}+1}\right)=e^{-\gamma^{\prime}(1) r t}=0
$$

Proof See the Appendix.

What happens to the consumer equilibrium expectations coefficient, $\lambda$, when $\Delta$ shrinks? A numerical illustration is presented in Figure 3 below, where $\beta$ is measured along the horizontal axis, and $r \lambda$ is measured along the vertical axis (the picture is drawn for $r=1)$.

\section{FIGURE 3}

Notice that $r \lambda$ is increasing in $\beta .^{12}$ Interestingly, for any positive $\beta$, an increase in $\beta$ implies that for any given number of previous customers, $\bar{\theta}-\theta_{n}$, the rent which is to be left to marginal customer in any period $n$ (the lowest type among the first-time consumers in period $n$ ) increases, i.e., the rent increases as the length of the period of commitment shrinks. The reason is that as $\Delta$ gets smaller, the marginal first-time customers has a stronger incentive to delay the first purchase to the following period, unless this incentive is countered by giving them more rent. In the limit as $\Delta \rightarrow 0, \lambda \rightarrow 1$ (this is shown easily by using L'Hospital's rule: the ratio of the first-order derivatives of the numerator and denominator of $(24)$ equals in the limit $\frac{\gamma^{\prime}(1)}{1+\gamma^{\prime}(1)}=1$ as $\left.\gamma^{\prime}(1)=+\infty\right)$. In other words, in the limit, the consumers capture all the benefits of the relationship and no profit is left to the monopolist.

Let us confirm this claim. The monopolist's equilibrium aggregate profit, or value of the firm (i.e., the sum of all future discounted profits), as viewed at time $t=0$, can be easily expressed as a function of $\beta$, as given below: ${ }^{13}$

\footnotetext{
${ }^{12} \mathrm{As} \beta \rightarrow 0$ (meaning $\Delta \rightarrow \infty$, i.e., the commitment interval is infinite), we see $\gamma \rightarrow 1 / 2$ and $\lambda \rightarrow 0$. This means that when the commitment period is infinite, the firm serves only customers whose type $\theta$ belongs to $\left[\frac{1}{2} \bar{\theta}, \bar{\theta}\right]$, and the rent of the lowest type that is not excluded, type $\theta_{c}=(1 / 2) \bar{\theta}$, is zero.

${ }^{13}$ In this formula, we set $\bar{\theta}=1$ and $\underline{\theta}=0$.
} 


$$
\Pi(\beta)=\frac{1}{r}\left(\frac{(1-\beta) \gamma^{*}(\beta)\left[1-\gamma^{*}(\beta)\right]}{\left[1-\beta \gamma^{*}(\beta)\right]\left[1-\beta \gamma^{*}(\beta)^{2}\right]}\right) .
$$

The relationship between $\Pi$ and $\beta$ is pictured in Figure 4 below. ${ }^{14}$ The $x$-axis represents $\beta$, whereas the $y$-axis depicts equilibrium aggregate profit (П).

\section{FIGURE 4}

The figure shows that the aggregate profit is decreasing in $\beta$, i.e., it is increasing in the length of the period $\Delta$ of commitment. This result is intuitively plausible: one expects that aggregate profit is greatest when the monopolist can fully commit right from the beginning to a sequence of contracts. (As we shall show in the next section, this implies sticking forever to the monopolist's initial price.) Intuitively, the opportunity of reoptimize repeatedly very soon would be detrimental to the firm, because rational customers would then expect that they do not have to wait very long to benefit from the future surplus, and accordingly they would buy in the current period only if they are offered greater current rents (lower prices) to purchase in the current period.

When $\Delta$, the length of the commitment period between two contractual offers, tends toward infinity (so that $\beta \rightarrow 0$ ), $\Pi(0)=\frac{1}{4 r}$. This is equivalent to an infinite repetition of the static equilibrium. For the other polar case, where $\beta \rightarrow 1$ (i.e., $\Delta \rightarrow 0$ ), Claim 2 below states formally that the limit of $\Pi(\beta)$ when $\Delta \rightarrow 0$ is equal to 0 . This is again a Coasian result but in our set-up it applies to a monopolist producing a non-durable good (instead of the durable goods case already studied in the literature). The Coase Conjecture indeed states that in the limiting case where the time interval that elapses between two offers tends to zero, the durable-good monopolist's equilibrium price is equal to the constant marginal cost, i.e., the profit is zero.

Claim 2 The aggregate profit falls as $\Delta$ decreases, and tends toward zero as $\Delta$ tends toward zero.

Proof: See the Appendix.

\footnotetext{
${ }^{14}$ The picture is drawn for $r=1$ (or, alternatively, the figure depicts $r \Pi(\beta)$ for any value of $r$ ).
} 


\section{Comparison with the case of commitment}

Suppose now that, contrary to what has been assumed in the preceding sections, the monopolist is able to commit, right from the beginning, to a sequence of pre-determined prices. This commitment capability is supposed to include the ability to commit both with regard to the price charged to new customers and to the prices charged the different groups of former customers, who are segmented according to the date of first purchase. Thus, at time $t=0$, the monopolist announces (i) the old-customer prices $p(n+j, n)$ that it will offer at any future period $n+j(j=1,2,3 \ldots)$ to consumers who will have first bought the good in period $n$ and (ii) the new-customer prices $p(n, n)$ that it will offer at each period $n$ to consumers who have not already purchased it. When solving for the optimal sequence of pre-determined contracts, the monopolist has no knowledge of any consumer.

Let us consider consumers who are first-time buyers in period $n$. They face (a) a price $p(n, n)=p_{n}^{N}$, when buying for the first time in period $n$ and (b) a price $p(n+j, n)=p_{n}^{O}$, $\forall j \geq 1$ for purchasing in all the remaining periods $n+j$ (the superscript $N$ and $O$ stand for new customers and old customers, respectively). ${ }^{15}$ These contract offers are determined and announced from the outset, i.e., at time $t=0$.

For heuristic reasons, we first consider the fictitious case when not only the monopolist but the consumers as well commit initially, i.e., we suppose provisionally that when a customer purchases the good for the first time (say in period $n$ ), she commits to purchase the good not only at all points of time during period $n$ at the price $p_{n}^{N}$, but also to purchase in subsequent periods as well, at the price $p_{n}^{O}$ that was initially agreed on. Technically, this means that we only need to consider consumers' initial participation constraints: they are not allowed to renege later on their contractual commitments. (Later, we will show that when we remove this supposition of commitment by customers, the monopolist's optimal path and consumers' equilibrium choices are not affected).

Under this assumption of commitment, let $U_{n}\left(\theta_{n+1}\right)$ denote the marginal customers' intertemporal net utility in period $n$ (that results from all purchases from period $n$ on):

\footnotetext{
${ }^{15}$ Allowing contract offers to old customers to be possibly different across periods would not change the results.
} 


$$
\begin{aligned}
U_{n}\left(\theta_{n+1}\right) & =\frac{1-\beta}{r}\left(\theta_{n+1}-p_{n}^{N}\right)+\frac{\beta}{r}\left(\theta_{n+1}-p_{n}^{O}\right) \\
& =\frac{1}{r} \theta_{n+1}-\left[\frac{1-\beta}{r} p_{n}^{N}+\frac{\beta}{r} p_{n}^{O}\right] .
\end{aligned}
$$

Then, for all $\theta \in\left[\theta_{n}, \theta_{n+1}\right]$, we have

$$
U_{n}(\theta)=\frac{1}{r} \theta-\left[\frac{1-\beta}{r} p_{n}^{N}+\frac{\beta}{r} p_{n}^{O}\right] \text { for } \theta \in\left[\theta_{n}, \theta_{n+1}\right]
$$

that is,

$$
U_{n}^{\prime}(\theta)=\frac{1}{r} \text { for } \theta \in\left[\theta_{n}, \theta_{n+1}\right]
$$

Thus

$$
U_{n}\left(\theta_{n}\right)=U_{n}\left(\theta_{n+1}\right)+\int_{\theta_{n+1}}^{\theta_{n}} \frac{1}{r} d \theta=U_{n}\left(\theta_{n+1}\right)+\frac{1}{r}\left(\theta_{n}-\theta_{n+1}\right) .
$$

Since $\theta_{n+1}$ is the period $n$ marginal customer, she must obtain the same intertemporal utility whether she chooses to be a first-time consumer in period $n$ or to be a first-time consumer in period $n+1$, i.e;

$$
U_{n}\left(\theta_{n+1}\right)=\beta U_{n+1}\left(\theta_{n+1}\right)
$$

Using (29) and (30), we obtain

$$
U_{n}\left(\theta_{n+1}\right)=\beta\left(U_{n+1}\left(\theta_{n+2}\right)+\frac{1}{r}\left(\theta_{n+1}-\theta_{n+2}\right)\right) .
$$

From (31), it follows that

$$
U_{n}\left(\theta_{n+1}\right)=\frac{1}{r} \sum_{j=1}^{\infty} \beta^{j}\left(\theta_{n+j}-\theta_{n+j+1}\right) .
$$

The aggregate profit (discounted to the beginning of period $n$ ) which the monopolist makes from vintage-n consumers (i.e., from those who are first-time consumers in period $n$ ) over their whole life time is 


$$
\pi_{n}=\left[F\left(\theta_{n}\right)-F\left(\theta_{n+1}\right)\right]\left[\frac{1-\beta}{r} p_{n}^{N}+\frac{\beta}{r} p_{n}^{O}\right] .
$$

Using (28), this is equivalently written as

$$
\pi_{n}=\left[F\left(\theta_{n}\right)-F\left(\theta_{n+1}\right)\right]\left[\frac{\theta_{n+1}}{r}-U_{n}\left(\theta_{n+1}\right)\right] .
$$

The aggregate discounted profits is the sum of discounted profits from all vintages:

$$
\Pi^{C} \equiv \sum_{n=0}^{\infty} \beta^{n} \pi_{n} .
$$

Using (32), this can be rewritten as

$$
\Pi^{C} \equiv \frac{(1-\beta)}{r} \sum_{n=0}^{\infty} \beta^{n}\left(1-F\left(\theta_{n+1}\right)\right) \theta_{n+1} .
$$

Point-wise maximization with respect to $\theta_{n+1}$ leads to $\theta_{n+1}=\theta^{* *}, \forall n \geq 0$, where $\theta^{* *}$ is the solution of

$$
\left(1-F\left(\theta^{* *}\right)\right)-f\left(\theta^{* *}\right) \theta^{* *}=0 .
$$

Thanks to Assumptions 1 and 2 such a solution exists and is interior, i.e., $\theta^{* *} \in(\underline{\theta}, \bar{\theta})$. (In the uniform distribution case with $\underline{\theta}=0$, we have $\theta^{* *}=\frac{\bar{\theta}}{2}$.) This implies that in the initial period $(n=0)$, the monopolist sells only to those consumers with $\theta \in\left[\theta^{* *}, \bar{\theta}\right]$, and in subsequent periods, $n=1,2,3 \ldots$, only these old customers are served. In other words, $\theta_{1}=\theta^{* *}$, and the monopolist does not expand the market coverage after the initial period. This result, together with (32), implies that $U_{0}\left(\theta_{1}\right)=0$, i.e., the marginal customers are left with no surplus. Now, from (27), it follows that the equilibrium prices $p_{n}^{N}$ and $p_{n}^{O}$ must satisfy the condition

$$
\left(\frac{1-\beta}{r} p_{n}^{N}+\frac{\beta}{r} p_{n}^{O}\right)=\frac{\theta^{* *}}{r}, \forall n \geq 0 .
$$

Up to now, we supposed that the customers cannot renege on their initial contractual commitments: when vintage $n$ customers become "old customers" (in periods $n+j$, where $j \geq 1$ ) they are forced to buy at the contractual price $p_{n}^{O}$ even if they would be better off not buying. Notice that equation (35) does not determine uniquely $p_{n}^{N}$ and $p_{n}^{O}$ : only their 
weighted sum is determined. It is easy to see that the monopolist can set any $p_{n}^{O} \leq \theta^{* *}$ for all $n \geq 0$ to guarantee that all former customers always purchase the good, even when allowed to renege on initial agreements. Therefore, there is a continuum of commitment equilibrium prices, but they all correspond to the same extent of market coverage, the same consumers' intertemporal utilities and the same aggregate profit for the firm. At these equilibria, the consumers are offered the same weighted price for purchasing the good, independently of the period of their first purchase.

Proposition 2 If the monopolist can commit right from the start to any sequence of contract offers, then only consumers whose type $\theta$ belongs to the interval $\left[\theta^{* *}, \bar{\theta}\right]$ will be served, and they all make their first purchase in the initial period, $n=0$. Moreover,

(i) in all periods, they are offered the same time-invariant weighted price $\left(\frac{1-\beta}{r} p_{n}^{N}+\right.$ $\left.\frac{\beta}{r} p_{n}^{O}\right)=\frac{1}{r} \theta^{* *}$, with $p_{n}^{O} \leq \theta^{* *}$

(ii) the firm does not use the information it has acquired on first-time customers.

The equilibrium described in Proposition 2 is the infinite repetition of the static nondiscriminatory monopoly equilibrium. The firm defines its optimal sequence of contracts at the beginning of the game, at a time when it only knows the distribution of types and, therefore, it is unable to attribute a type neither to any specific individual customer nor to any group of customers. The monopolist thus optimally commits to refrain from selling to a new set of consumers in subsequent periods, and not to exploit in subsequent periods the knowledge it has acquired on its customers' preferences. Such a commitment has the effect of reducing the high type customers' informational rents by diminishing their incentives to delay their first purchase.

The monopolist's aggregate profit under commitment is then, from (33) and (34)

$$
\Pi^{C}=\frac{\left(\theta^{* *}\right)^{2} f\left(\theta^{* *}\right)}{r}
$$

This implies that in case of the uniform distribution, with $\bar{\theta}=1$ and $\underline{\theta}=0, \Pi^{C}=\frac{1}{4 r}$. Comparing with (26), we see that $\Pi^{C}>\Pi(\beta)$ if $0<\beta \leq 1$, which is of course to be expected. Our comparison of aggregate profits with and without price commitment, yielding $\Pi^{C}>\Pi(\beta)$ if $0<\beta \leq 1$, reveals our curse of knowledge result. The monopolist would be better off it did not have the possibility to keep records of the exact moment that each consumer enters the market. Indeed, if the monopolist were unable to collect 
(or keep) data about its consumers, it would neither segment the market (according to the time of consumers' first purchase) nor price discriminate among different cohorts of consumers, sticking to a uniform pricing strategy instead (and getting an aggregate profit equal to $\Pi^{C}>\Pi(\beta)$ if $\left.0<\beta \leq 1\right)$.

Obviously the optimal strategy under commitment is not time-consistent. In other words, if at some future time the firm is released from its commitment, it will have an incentive to deviate from its commitment. There are two reasons for this. First, if allowed to reoptimize, the monopolist would always benefit from using its data on the date of consumers first purchase to exercise third-order price discrimination over customers as identified by the date of their first purchase. Second, when allowed to change its offers to potential new customers in subsequent periods, it would benefit from selling to at least some of them in order to identify them and to be able to make profits from them in all subsequent periods. Rational customers who expect to benefit from better offers in the future would then delay their purchase to the next period unless they are granted lower present prices (higher rents). ${ }^{16}$

\section{Consumers Surplus and Welfare under MPE}

For the sake of simplicity, we specialize here to the uniform distribution with $\bar{\theta}=1$ and $\underline{\theta}=0$. Let $w(n)$ denote the social welfare at the MPE in period $n$ :

$$
w(n)=\frac{1}{r}\left[\int_{\gamma \Theta(n)}^{\Theta(n)} \theta d \theta\right]=\frac{1}{2 r}\left(1-\gamma^{2}\right) \Theta(n)^{2} .
$$

The aggregate discounted social welfare is

$$
W(\beta)=\sum_{n=0}^{\infty} \beta^{n} w(n) .
$$

Using $\Theta(n)=\gamma^{n}$, it follows that

$$
W(\beta)=\frac{\left(1-\gamma(\beta)^{2}\right)}{2 r\left(1-\beta \gamma(\beta)^{2}\right)},
$$

\footnotetext{
${ }^{16}$ A monopolist that can commit is in effect an "open-loop Stackelberg leader," and it is well-known that open-loop Stackelberg leaders are typically beset by time-inconsistency problem. For more detailed discussion, see Chapter 5 of Dockner et al. (2000), and Chapter 1 of Long (2010).
} 
where $\gamma=\gamma(\beta)$ is the solution of the Euler equation (23). In the limiting case where $\beta=0$, we obtain $\gamma=\frac{1}{2}$ and thus $W(0)=\frac{3}{8 r}$ (this is exactly the welfare under the commitment scenario analyzed in section 5). Figure 5 below shows that $W$ tends to increase as $\beta$ increases (that is, aggregate welfare increases as $\Delta$ tends to zero), though this not monotonic: welfare at first decreases as $\beta$ increases. ${ }^{17}$ Again, the $x$-axis represents $\beta$. The $y$-axis now measures the aggregate discounted social welfare.

\section{FIGURE 5}

One can show that $\lim _{\beta \rightarrow 1} W(\beta)=\frac{1}{2 r}$, which is greater than $W(0)$, consistent with Figure 5. ${ }^{18}$ Why does shortening the contractual period of commitment increases social welfare? On one hand, when $\Delta$ shrinks, $\gamma$ increases so that the rate of expansion of the market from one period to the next decreases On the other hand, the periods become shorter. The latter effect turns out to outweigh the former one.

\section{Conclusion}

We have shown that the acquisition of information about customers to implement third degree price discrimination based on customer recognition can hurt a monopolist. A monopolist would be better off by committing to a policy of not keeping any information about customers, so as to prevent his future selves from engaging in opportunistic behavior. In other words, it may pay to tie one's own hands.

We have illustrated this general point by using as a workhorse a dynamic extension of the static monopoly model, such that the monopolist may segment the set of infinitelylived consumers according to the date at which they purchased the good for the first time. In subsequent periods, the monopolist may offer different prices to different groups of customers. Within our dynamic framework of price discrimination based on customer recognition, we characterize the equilibrium of the dynamic game played between the

\footnotetext{
${ }^{17}$ The picture is drawn for $r=1$ (alternatively this is $r W(\beta)$ which is pictured).

${ }^{18}$ In evaluating $\lim _{\beta \rightarrow 1} W(\beta)$, we make use of L'Hospital's rule. The limit is ratio between the first order derivatives of the numerator and the denominator of $(36)$, i.e. $\frac{1}{r} \frac{\gamma^{\prime}(1)}{1+2 \gamma^{\prime}(1)}$. The proof is completed by appealing to thefact that $\gamma^{\prime}(1)=+\infty$.
} 
monopolist and its customers, under two alternative scenarios: the no-commitment and the full commitment scenario.

In the first case, we find that the lack of commitment on the part of the monopolist makes customers demand more information rents, and this is detrimental to the firm. In addition, we find that the Markov-Perfect Equilibrium of the game exhibits Coasian dynamics: the market is covered instantaneously and the monopolist's profit vanishes when the length of time between two different price offers shrinks to zero. By contrast, if the monopolist could credibly commit to any sequence of contract offers, it would find it optimal to commit to a policy of non-discrimination between new and old customers and to stick forever to its initial contract offer. In fact, the commitment equilibrium is simply the infinite replication of the static equilibrium without consumer recognition.

Comparing equilibrium aggregate profits in the two alternative outcomes (i.e. the price discrimination outcome arising under no-commitment and the uniform pricing outcome arising with full commitment), our analysis demonstrates that the firm is paradoxically hurt if it has the ability to recognize its consumers and use such information to price discriminate among different consumer segments. This is what we call the curse of knowledge: there is such a thing as blessed ignorance. When consumers have rational expectations, the monopolist would wish to be able to commit not to exploit the information it acquires on its previous customers. This suggests that in some monopoly markets firms may actually benefit from public policies designed to limit firms' ability to collect and keep data records about their customers (e.g. the General Data Protection Regulation (GDPR) in the EU).

\section{APPENDIX \\ Proof of Proposition 1}

Equation (23) follows directly from (19). It defines the equilibrium value of $\gamma(\beta)$ as the solution of a fourth order polynomial. As shown in Figure 1, (23) has one positive solution for all $\beta>0$. It has also a negative one but only the former can be a valid solution. Accordingly $\gamma(\beta)$ is strictly increasing in $\beta$, from $\gamma=\frac{1}{2}$ when $\beta=0$ to $\gamma=1$ when $\beta=1$.

\section{Proof of Claim 1}

Since $\gamma(1)=1, \lim _{\Delta \rightarrow 0}\left(\gamma\left(e^{-r \Delta}\right)\right)^{\frac{t}{\Delta}+1}=\lim _{\Delta \rightarrow 0}\left(\gamma\left(e^{-r \Delta}\right)\right)^{\frac{t}{\Delta}}$. Notice that $\ln \left(\gamma\left(e^{-r \Delta}\right)\right)^{\frac{t}{\Delta}}=$ $\frac{t}{\Delta} \ln \left(\gamma\left(e^{-r \Delta}\right)\right)$. Since that $\gamma(1)=1, \frac{t}{\Delta} \ln \left(\gamma\left(e^{-r \Delta}\right)\right)$ is undefined when $\Delta=0$. Then, in 
order to determine the limit value of $\frac{\ln \left(\gamma\left(e^{-r \Delta}\right)\right)}{\Delta}$ when $\Delta \rightarrow 0$, we have to use L'Hospital's rule and evaluate the ratio of the derivatives of the numerator and the denominator at $\Delta=0$. This ratio turns out to be equal to $-r \gamma^{\prime}(1)$. It follows that $\lim _{\Delta \rightarrow 0}\left(\gamma\left(e^{-r \Delta}\right)\right)^{\frac{t}{\Delta}}=$ $e^{-r \gamma^{\prime}(1) t}$.

Now let us determine $\gamma^{\prime}(1)$. Differentiating the identity $(23)$, we obtain $E_{\beta}^{\prime}(\beta, \gamma(\beta))+$ $E_{\gamma}^{\prime}(\beta, \gamma(\beta)) \gamma^{\prime}(\beta)=0$. Remembering that $\gamma(1)=1$, it turns out that $E_{\beta}^{\prime}(1, \gamma(1))=$ $E_{\gamma}^{\prime}(1, \gamma(1))=0$ so that the ratio $-\frac{E_{\beta}^{\prime}(1, \gamma(1))}{E_{\gamma}^{\prime}(1, \gamma(1))}$ is undetermined. Again, we need to use L'Hospital's rule to find the value of $\gamma^{\prime}(1)$. Then, we have to differentiate the numerator and the denominator to finally obtain $\gamma^{\prime}(\beta) \rightarrow+\infty$ as $\beta \rightarrow 1$. It follows that $\lim _{\Delta \rightarrow 0}\left(\gamma\left(e^{-r \Delta}\right)\right)^{\frac{t}{\Delta}}=0$

\section{Proof of Claim 2}

According to equation (26), the value of $\Pi(\beta)$ is undetermined when $\beta=1$ since both the numerator and the denominator equal zero. Let us then apply L'Hospital's rule. The ratio of the first order derivatives of the numerator and the denominator is again undetermined. So we consider the ratio of the second order derivatives. It is equal to

$$
\frac{\gamma^{\prime}(1)}{\left(1+2 \gamma^{\prime}(1)\right)\left(1+\gamma^{\prime}(1)\right)}
$$

Using the fact that $\gamma^{\prime}(1)=+\infty$, we obtain $\Pi(1)=0$.

Derivation of eq (33), using the expression for $\pi_{n}$, we obtain

$$
\Pi^{C}=\beta^{0}\left[F(\bar{\theta})-F\left(\theta_{1}\right)\right]\left[\frac{\theta_{1}}{r}-U_{0}\left(\theta_{1}\right)\right]+\beta^{1}\left[F\left(\theta_{1}\right)-F\left(\theta_{2}\right)\right]\left[\frac{\theta_{2}}{r}-U_{1}\left(\theta_{2}\right)\right]+\ldots e t c
$$

Substituting for $\left[\frac{\theta_{1}}{r}-U_{0}\left(\theta_{1}\right)\right]$ and $\left[\frac{\theta_{2}}{r}-U_{1}\left(\theta_{2}\right)\right]$ etc.,, we obtain

$$
\begin{aligned}
& {\left[\frac{\theta_{1}}{r}-U_{0}\left(\theta_{1}\right)\right]=\frac{\theta_{1}}{r}-\beta\left(\frac{\theta_{1}-\theta_{2}}{r}\right)-\beta^{2}\left(\frac{\theta_{2}-\theta_{3}}{r}\right)+\ldots} \\
& {\left[\frac{\theta_{2}}{r}-U_{1}\left(\theta_{2}\right)\right]=\frac{\theta_{2}}{r}-\beta\left(\frac{\theta_{2}-\theta_{3}}{r}\right)-\beta^{2}\left(\frac{\theta_{3}-\theta_{4}}{r}\right)+. .}
\end{aligned}
$$


Cancelling out terms, we finally get

$$
\begin{aligned}
\Pi^{C}= & \beta^{0} F(\bar{\theta})\left(\frac{1-\beta}{r} \theta_{1}\right)+\beta F(\bar{\theta}) \frac{(1-\beta)}{r} \theta_{2}+\beta^{2} F(\bar{\theta}) \frac{(1-\beta)}{r} \theta_{3} \text { etc. } \\
& -F\left(\theta_{1}\right)\left(\frac{1-\beta}{r} \theta_{1}\right)-\beta F\left(\theta_{2}\right)\left(\frac{1-\beta}{r}\right) \theta_{2}-\beta^{3} F\left(\theta_{2}\right)\left(\frac{1-\beta}{r}\right) \theta_{3} \text { etc. }
\end{aligned}
$$

\section{References}

[1] Bond, E., and L. Samuelson, (1987), The Coase conjecture need not hold for durable good monopolies with depreciation. Economics Letters 24:93-97.

[2] Bulow, J. I., (1982), "Durable Goods Monopolists", Journal of Political Economy, 90(2), 314-32.

[3] Chen, Y. (1997), "Paying Customers to Switch," Journal of Economics and Management Strategy, 6, 877-897.

[4] Chen, Y., and Pearcy, J. (2010): "Dynamic Pricing: when to Entice Brand Switching and when to Reward Consumer Loyalty," RAND Journal of Economics, 41, 674-685.

[5] Choe, C., S. King, N. Matsushima (2018), Pricing with Cookies: Behavior-Based Price Discrimination and Spatial Price Competition. Management Science 64(12): 5669-5687.

[6] Coase, R., 1972, "Durability and Monopoly, Journal of Law and Economics, 15, 143-149.

[7] Dockner, E., S. Jorgensen, N. V. Long, and G. Sorger (2000), Differential Games in Economics and Management Science. Cambridge University Press, Cambridge, U.K.

[8] Driskill, R. and S. McCafferty, (2001) Monopoly and oligopoly provision of addictive goods. International Economic Review 42(1): 43-72.

[9] Esteves, R.B. (2009), "Price Discrimination with Partial Information: Does it payoff?" Economics Letters, 105, 28-31 
[10] Esteves, R.B. (2010), "Pricing with customer recognition." International Journal of Industrial Organization, Vol. 28 (6), 669-681.

[11] Fudenberg, D. and J. Tirole (2000), Customer Poaching and Brand Switching. Rand Journal of Economics, 31(4), 634-657.

[12] Fudenberg, D. and J.M. Villas-Boas (2006), Behavior-Based Price Discrimination and Customer Recognition. In T. Hendershot (ed.), Economics and Information Systems, Vol. 1, Ch.7. Elsevier.

[13] Fudenberg, D. and J.M. Villas-Boas (2012), Price Discrimination in the Digital Economy. In M. Peitz and J. Waldfogel (eds.), Oxford Handbook of the Digital Economy, Ch. 10. Oxford University Press, Oxford, UK.

[14] Gehrig, T., Shy, O and Stenbacka, R. (2011), History-Based Price Discrimination and Entry in Markets with Switching Costs, European Economic Review 55, 732-739.

[15] Gehrig, T., Shy, O and Stenbacka, R. (2012), A Welfare Evaluation of History-Based Price Discrimination, Journal of Industry, Competition and Trade 12, 373-393.

[16] Kahn, C., 1987, "The Durable Goods Monopolist and Consistency with Increasing Costs," Econometrica, 54, 274-294.

[17] Karp, L., (1996), Depreciation erodes the Coase conjecture. European Economic Review 40: 473-490.

[18] Laussel, D., M. de Montmarin, and N. V. Long, (2004), Dynamic duopoly with congestion effects. International Journal of Industrial Organization 22 (5): 655-677.

[19] Laussel, D., N. V. Long and J. Resende (2015), Network Effects, Aftermarkets and the Coase Conjecture. International Journal of Industrial Organization, Vol. 41: 8496.

[20] Long, N. V. (2015), Dynamic Games Between Firms and Infinitely-lived Consumers: A Review of the Literature. Dynamic Games and Applications, Vol. 5(4): 467-492.

[21] Mohammed, R. (2017), "How Retailers Use Personalized Prices to Test What You're Willing to Pay", Harvard Business Review, October 20. 
[22] Tirole, J. (1988), The Theory of Industrial Organization. MIT Press.

[23] Villas-Boas, M. (1999), "Dynamic Competition with Customer Recognition." RAND Journal of Economics, 30, 604-631. 


\section{FIGURES}

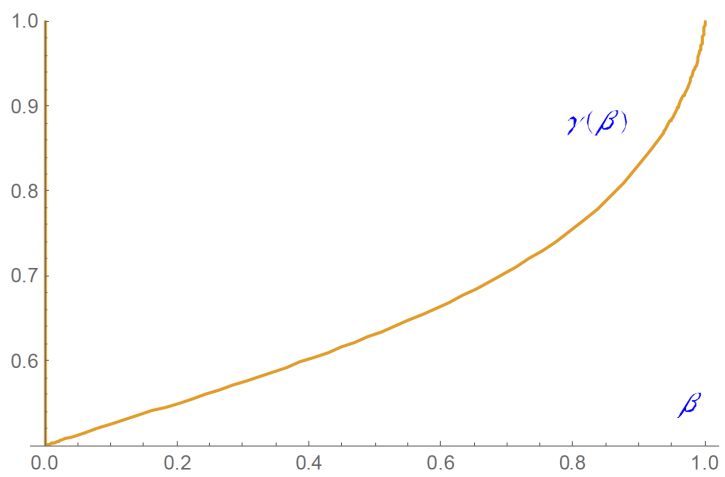

Figure 1. Equilibrium cut-off rule $\gamma(\beta)$

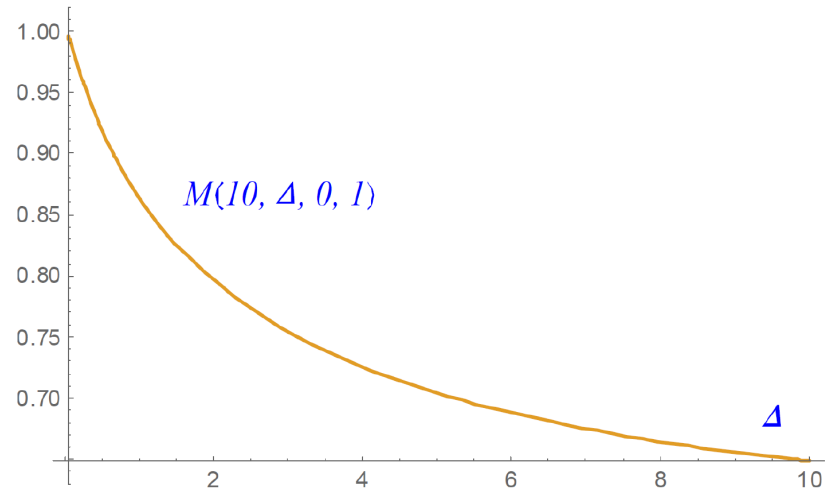

Figure 2. Market Coverage as a function of $\Delta$. 


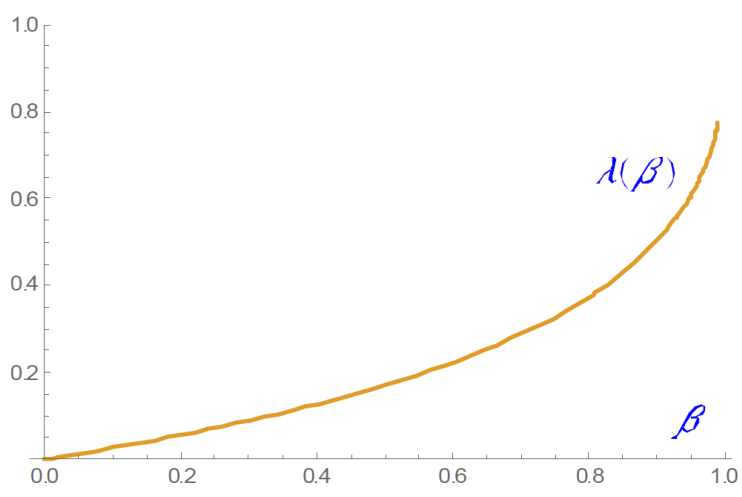

Figure 3. Equilibrium expectations rule $\lambda(\beta)$.

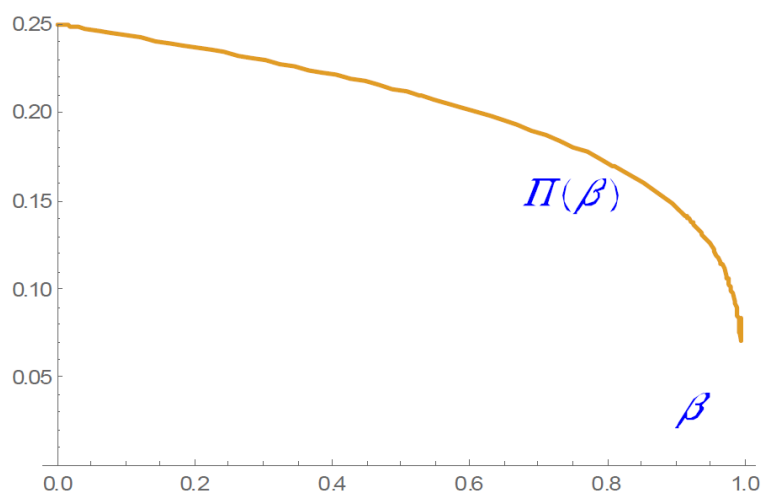

Figure 4. Equilibrium aggregate profit $\Pi(\beta)$. 


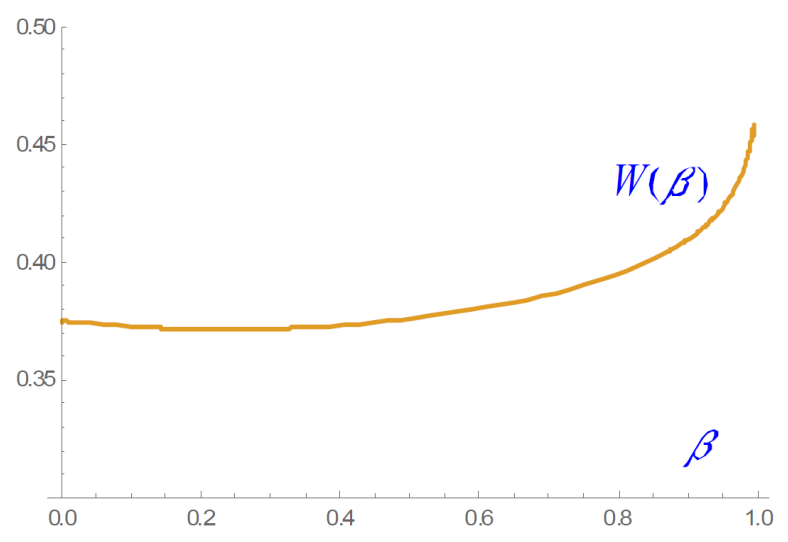

Figure 5. Equilibrium aggregate social welfare, $W(\beta)$. 